\title{
Model uncertainty-based evaluation of process strategies during scale-up of biopharmaceutical processes
}

\author{
Johannes Möller ${ }^{\mathrm{a}, *}$, Tanja Hernández Rodríguez ${ }^{\mathrm{c}}$, Jan Müller ${ }^{\mathrm{b}}$, Lukas Arndta, \\ Kim B. Kuchemüller ${ }^{\mathrm{a}}$, Björn Frahm ${ }^{\mathrm{c}}$, Regine Eibl ${ }^{\mathrm{b}}$, Dieter Eibl ${ }^{\mathrm{b}}$, Ralf Pörtner ${ }^{\mathrm{a}}$ \\ ${ }^{a}$ Hamburg University of Technology, Bioprocess and Biosystems Engineering, Hamburg, Germany \\ ${ }^{\mathrm{b}}$ Zurich University of Applied Sciences, School of Life Sciences and Facility Management, Chemistry and Biotechnology, Wädenswil, Switzerland \\ ${ }^{c}$ Ostwestfalen-Lippe University of Applied Sciences and Arts, Biotechnology and Bioprocess Engineering, Lemgo, Germany
}

\section{A R T I C L E I N F O}

\section{Article history:}

Received 3 August 2019

Revised 29 November 2019

Accepted 21 December 2019

Available online 23 December 2019

\section{Keywords:}

Monte Carlo methods

Process modeling

Parameter distributions

Process validation

Model-assisted design of experiments

Quality by design

\begin{abstract}
A B S T R A C T
Reliable scale-up of biopharmaceutical production processes is key in Quality by Design. In this study, a model-based workflow is described to evaluate the bioprocess dynamics during process transfer and scale-up computationally. First, a mathematical model describes the bioprocess dynamics of different state variables (e.g., cell density, titer). Second, the model parameter probability distributions are determined at different scales due to measurement uncertainty. Third, the quantified parameter distributions are statistically compared to evaluate if the process dynamics have been changed. This workflow was tested for the scale-up of an antibody-producing $\mathrm{CHO}$ fed-batch process. Significant differences were identified between the process development $(30 \mathrm{ml})$ and implementation $(250 \mathrm{ml})$ scale, and the feeding strategy was validated using model-assisted Design of Experiments. Then, the validated process strategy was successfully scaled up to 21 laboratory and 501 pilot scale. In summary, the proposed workflow enables a knowledge-driven evaluation tool for bioprocess development.
\end{abstract}

(c) 2020 Elsevier Ltd. All rights reserved.

\section{Introduction}

Reliable design and scale-up of biopharmaceutical production processes with mammalian cell culture are essential in Quality by Design (QbD). First, a stable and productive process needs to be identified during process development after clone selection. This includes screening studies of medium components (Torkashvand et al., 2015; Rouiller et al., 2014) and the definition of a stable and effective process strategy (e.g. fed-batch) (Wurm, 2004; Gmeiner et al., 2015). Mathematical process modeling is an efficient tool during this step because it includes the most important mechanistics of the biological system. Moreover, mathematical process models describe the interactions between process parameters and key performance indicators, which is a substantial part of QbD (Guideline, 2009; Herwig et al., 2015; Carrondo et al.,

Abbreviations: Ab, antibody; Amm, ammonium; BR, bioreactor; $\mathrm{CI}$, confidence interval; CFD, computational fluid dynamics; $\mathrm{CHO}$, Chinese hamster ovary; DAPI, 4',6-diamidino-2-phenylindole; Glc, glucose; Gln, glutamine; Lac, lactate; MC, Monte Carlo; mDoE, model-assisted Design of Experiments; NRMSD, normalized root mean square deviation; QbD, Quality by Design; RAD, relative average deviation; RSM, response surface model; SF, shake flask.

* Corresponding author.

E-mail address: johannes.moeller@tuhh.de (J. Möller).
2012). More process knowledge is incorporated during modeling if uncertainty quantification is performed, i.e. determining the effect of input uncertainties (e.g. experimental variations) on model outcomes (Anane et al., 2019; Liu and Gunawan, 2017; Sin et al., 2009). Uncertainty-based modeling techniques have been widely used in chemical systems or systems biology (Möller et al., 2018, 2019), but not often in bioprocess simulation studies (Hernández Rodríguez et al., 2019).

Second, the bioprocess including its process strategy needs to be scaled up, for which mostly data-driven approaches are used. This is conventionally done by keeping a hydrodynamic state constant, e.g. volumetric power input $\left(P / V_{\mathrm{L}}\right)$ (Klöckner et al., 2012; Catapano et al., 2009), mixing time (Varley and Birch, 1999; Rosseburg et al., 2018), impeller tip speed (Ju and Chase, 1992; Alsayyari et al., 2018) or the volumetric mass transfer coefficient $k_{L} a$ (Xing et al., 2009; Nienow et al., 1996). Therefore, it is recommended to hydrodynamically characterize the bioreactors at each scale (recommendation see Meusel et al., 2016). Additionally, computational fluid dynamics (CFD) has gained rising importance to obtain an improved understanding of the bioreactor hydrodynamics from small to large scale (Sharma et al., 2011; Werner et al., 2014; Kaiser et al., 2011; Nienow et al., 2013). However, the cellular behavior including metabolism and productivity could vary at different bioreactor scales due to e.g. differences in the hydrodynamic stress (Sieck 


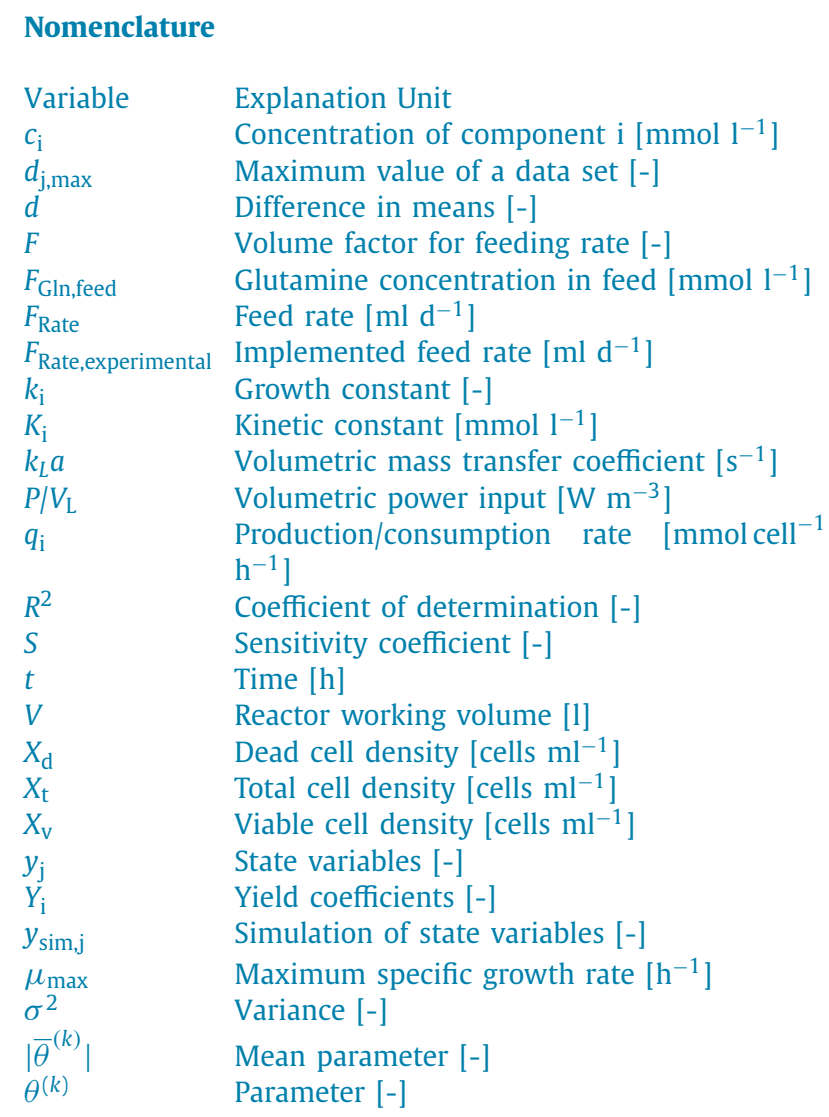

et al., 2013; Neunstoecklin et al., 2015) or pH gradients (Ivarsson et al., 2015; Brunner et al., 2017). So far, purely data-based scale-up procedures do not consider the dynamics of the bioprocess. Therefore, it is not ensured that the previously developed process strategy is scaled up sufficiently and that the process dynamics stay constant during scale-up.

In this study, a workflow is introduced to computationally evaluate the process dynamics, described by a mathematical process model, at different bioreactor scales. This concept is based on the determination and statistical comparison of the probability distributions of model parameters under consideration of experimental uncertainty. Thus, the model incorporates the current process understanding and enables a knowledge-driven decision making. The workflow is tested for the model-based evaluation of an antibodyproducing $\mathrm{CHO}$ fed-batch cultivation process during the scale-up from process development scale ( $30 \mathrm{ml}$ shake flask) to process implementation at $250 \mathrm{ml}$ and 21 bioreactor scale. Finally, it is shown how the mathematical model is used to determine the operating range during the process transfer to a 501 pilot scale bioreactor.

\subsection{Proposed model uncertainty-based workflow}

As can be seen at the beginning of Fig. 1, experimental data sets at two different bioprocess scales are used as input (exemplary Scale A and Scale B), e.g. process development and process implementation scale (typically using different bioreactor systems). Please notice that this study does not focus on how the scale-up needs to be performed hydrodynamically. The aim was to develop a method to statistically evaluate if the process dynamics are comparable at both scales and if the targeted process optimum (i.e. process strategy) is still met.

The basis of the introduced concept is the quantification of model-parametric uncertainties under consideration of experimen- tal uncertainty due to variability in measurements (box 1). The model parameters are estimated multiple times (Monte Carlo sampling) for each investigated scale under the assumption of normally distributed measurement errors for each observable to determine the parameter distributions. Then, the parameter distributions and the prediction quantiles are used to visualize the process variability based on the model parameter distributions (box 2). In the next step (box 3), a statistical comparison of the parameter distributions is performed to evaluate if there are statistically significant differences between both scales. The same process dynamics and targeted process strategy could be ensured if no changes in the parameter distributions are identified. Otherwise, if the parameters differ significantly, a validation of the process strategy is recommended (box 4, e.g. adjusting the feed composition). In this validation step, a previously introduced model-assisted Design of Experiments ( $\mathrm{mDoE}$ ) concept is used to re-adjust the process strategy with a reduced number of experiments (Möller et al., 2019b). Based on this, it is recommended to enter further process development/process optimization studies or to proceed with scale-up if the validation was successful. This reflects a knowledge-driven methodology in QbD and can be repeated for every scale-up step individually.

\section{Materials and methods}

The process design scaled up in this study was generated at the Institute of Bioprocess and Biosystems Engineering (Hamburg University of Technology-TUHH) and was then transferred to the Institute of Chemistry and Biotechnology (Zurich University of Applied Sciences-ZHAW) for scale-up. Therefore, slightly different cultivation protocols and analytical methods were applied during this study.

\subsection{Mathematical process model}

An unstructured and non-segregated mechanistic process model was used in this study to compare the dynamics of the investigated process at different scales. It was previously described in Kern et al. (2016), Möller et al. (2019b) and Kuchemüller et al., 2020. In brief, the model describes cell growth $\left(X_{t}-\right.$ total cell density, $X_{\mathrm{d}}$ - dead cell density, $X_{\mathrm{v}}$ - viable cell density) and cell death based on the concentrations of glucose $\left(c_{\mathrm{Glc}}\right)$ and glutamine $\left(c_{\mathrm{Gln}}\right)$ and growth inhibition due to ammonium $\left(c_{\mathrm{Amm}}\right)$. The progression of the glucose and glutamine concentrations are coupled to the formation of lactate $\left(c_{\mathrm{Lac}}\right)$ and ammonium. The antibody $\left(c_{\mathrm{Ab}}\right)$ is modeled to be expressed constantly per cell. The model also includes the mass balances involved in the bolus fed-batch processes and the model equations are summarized in Supplementary Table 1 for easier reference. All computational methods in this study were performed in MATLAB 2018a.

\subsection{Monte Carlo-based uncertainty quantification}

The core of the proposed method is the quantification of parametric model uncertainties and comparison of these probability distributions at different bioreactor scales based on the experimental variability. Therefore, a normally distributed observational error of $5 \%$ relative standard deviation was assumed based on the typical measurement standard deviations of analytical methods in bioprocess evaluation (i.e. expert knowledge) (Wechselberger et al., 2013). In order to propagate this input uncertainty onto parametric uncertainty, Monte Carlo samples were generated (observational error) and the model parameters were adapted using the NelderMead optimization algorithm (Nelder and Mead, 1965; Singer and Singer, 2004). The objective/cost function was the weighted sum 


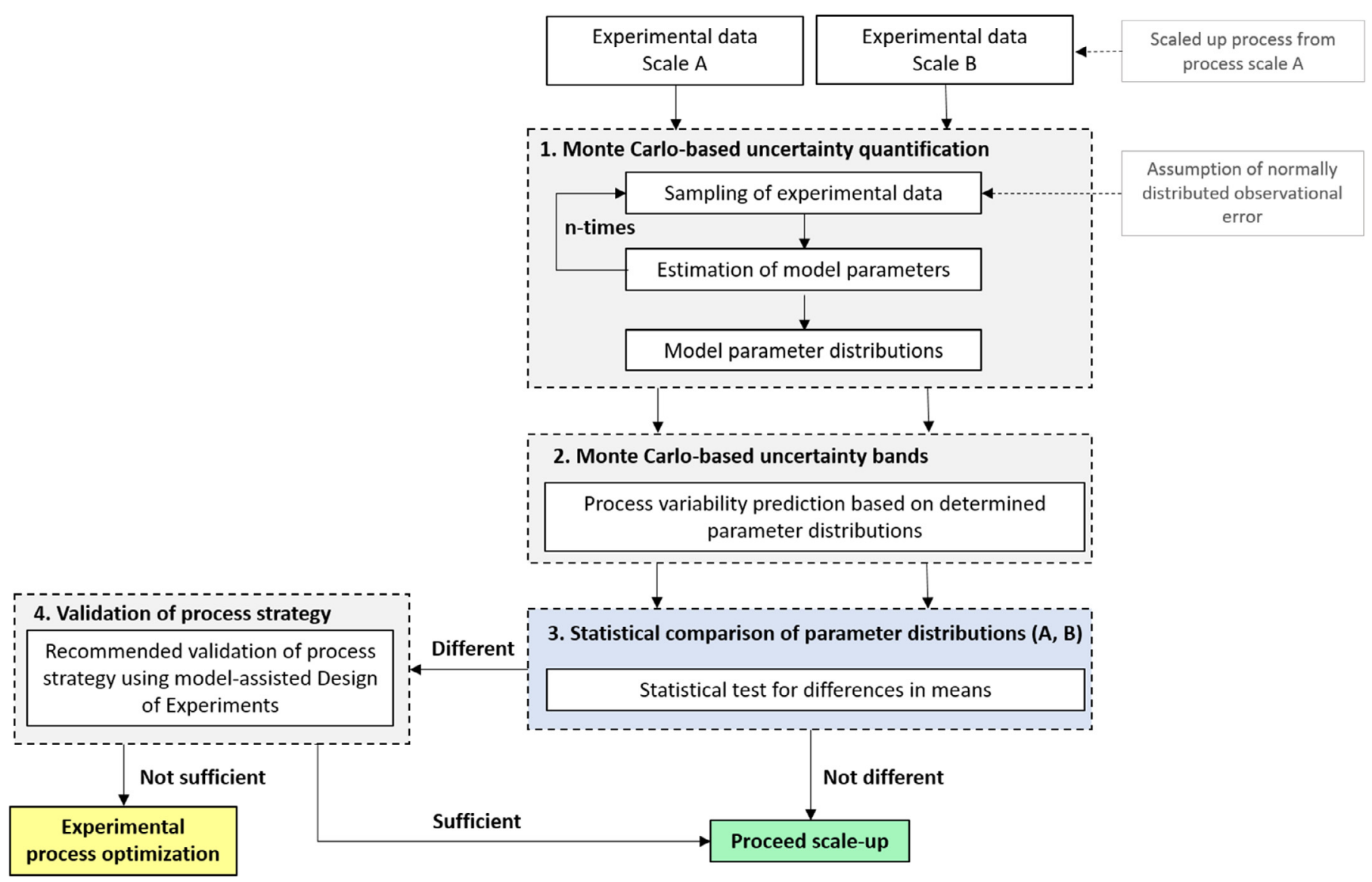

Fig. 1. Proposed uncertainty-based workflow for the evaluation of scale-up.

of squared residuals between the simulations $\left(y_{\operatorname{sim}, j}\left(t_{i}\right)\right)$ in comparison to the experimental data $\left(y_{j}\left(t_{i}\right)\right)$ over all time points $t_{1}, \ldots, t_{N}$ and all variables $y_{1}, \ldots, y_{M}$, normalized on the squared assumed measurement variance $\sigma_{\mathrm{j}}^{2}$, which is defined as $5 \%$ of the maximum value of a data set $\left(y_{j, \max }\right)$ for the $j$-th observable (i.e. $\sigma_{j}=$ $0.05 \cdot d_{\mathrm{j}, \max }$, maximum value of data set $\mathrm{j}$ ). The experimental data was sampled 1000 times and the model parameters were adapted for each sampling. The initial values are shown in Supplementary Table 2 and were the same in all compared scales. $X_{\mathrm{V}}$ and $c_{\mathrm{Ab}}$ were weighted with 100 and $c_{\text {Amm }}$ with 10.4 out of 29 experiments were randomly sampled and the parameters were estimated for the experiments performed during the identification of the feeding strategy (shake flasks). In the other scales, all experimental data was used.

\subsection{Statistical comparison of probability distributions}

The means of the determined model parameter distributions were statistically compared for two different bioreactor scales (see Fig. 1, Scale A and Scale B, respectively) to identify changes in the process dynamics. Therefore, the relative 95\%-confidence interval $(\mathrm{CI})$ for the difference in means was calculated. For two samples $x_{1}, \ldots, x_{n}$ and $y_{1}, \ldots, y_{m}$ (representing the distribution of one model parameter at two different scales) the means $\bar{x}$ and $\bar{y}$ and the sample variances $\sigma_{x}^{2}$ and $\sigma_{y}^{2}$ were computed. According to the central limit theorem, the difference in means $d=\bar{x}-\bar{y}$ of samples with large sample sizes follows a normal distribution, characterized by $\mathcal{N}\left(\bar{x}-\bar{y}, \sigma_{x}^{2} / n+\sigma_{y}^{2} / m\right)$. Then, the $95 \%$-confidence interval of the difference in means were calculated:

$\left[\bar{x}-\bar{y}-1.96 \sqrt{\sigma_{x}^{2} / n+\sigma_{y}^{2} / m}, \bar{x}-\bar{y}+1.96 \sqrt{\sigma_{x}^{2} / n+\sigma_{y}^{2} / m}\right]$.

In order to test for a statistically significant difference in means of at least 5\%, a model parameter was assigned to be significantly different, if the corresponding $\mathrm{CI}$ contains $5 \%$.

\subsection{Monte Carlo-based uncertainty bands}

Quantification and graphical representation of the propagated uncertainty in the process dynamics was performed with Monte Carlo methods, thus repeated simulations of the process with the 1000 previously determined parameter sets were carried out (2.2). The mean and the $10 \%$ and $90 \%$ quantiles of simulation were calculated with the function "prctile" (MATLAB 2018a, exact mode) (Langford, 2006).

\subsection{Validation of process strategy}

A validation of the process strategy (box 4 in Fig. 1) is recommended if the model parameter distributions (2.2) are significantly different. This is motivated based on the identified change of the bioprocess dynamics and is seen to support knowledgedriven decision making. Commonly, Design of Experiments (DoE) methods are applied to develop and validate the process strategy on different scales (e.g. during late stage process optimization) (Legmann et al., 2009; Brunner et al., 2017; Abt et al., 2018). Möller et al., (2019b) proposed a model-assisted DoE method, which combines mathematical process modeling with statistical 
Table 1

Summarized performed experiments in this study.

\begin{tabular}{lll}
\hline Aim & Number of cultivations & Working volume (cultivation system) \\
\hline Process development & 29 (2 blocks) & $30 \mathrm{ml}-50 \mathrm{ml}$ (shake flask, Corning, Netherlands) \\
Process implementation & 3 & $250 \mathrm{ml}$ (Ambr250, Sartorius Stedim Biotech, Germany) \\
Validation of process strategy & 4 & $250 \mathrm{ml}$ (Ambr 250) \\
Scale-up & 3 & 21 (UniVessel, Sartorius Stedim Biotech) \\
Scale-up & 1 & 501 (BIOSTAT STR50, Sartorius Stedim Biotech) \\
\hline
\end{tabular}

tools to significantly reduce the number of experiments. This concept was adapted in this study to validate the process strategy. In brief, a DoE is planned using suitable software (here: DesignExpert 11) and the recommended experiments are simulated instead of being experimentally performed. The responses (e.g. titer) are included into the DoE evaluation with a quadratic response surface model (all hierarchical, $\alpha_{\text {out }}<0.1$, adjusted R-squared criteria). Please see (Möller et al., 2019b) and Kuchemüller et al., 2020 for more information about the general concept of $\mathrm{mDoE}$.

\subsection{Identifiability analysis}

Monte Carlo simulations were used to evaluate whether the parameters can be reliably estimated with acceptable accuracy (Miao et al., 2011). Therefore, the propagation of the input uncertainties onto the uncertainty in model simulations were quantified. For each model parameter, the whole sample of adapted values (representing the probability distribution of this model parameter) was considered and the average relative estimation deviation was computed. After adapting the model to each of the $N$ simulated data sets to obtain parameter estimates $\hat{\theta}^{(k)}$ for the $k$-th parameter, the sample mean of the $k$-th parameter $\bar{\theta}^{(k)}$ and the corresponding relative average deviation $\left(\operatorname{RAD}\left(\theta^{(k)}\right)\right)$ was computed according to:

$\operatorname{RAD}\left(\theta^{(k)}\right)=100 \% \cdot \frac{1}{N} \sum_{i=1}^{N} \frac{\left|\hat{\theta}_{i}^{(k)}-\bar{\theta}_{i}^{(k)}\right|}{\left|\bar{\theta}_{i}^{(k)}\right|}$.

A low RAD-value reflects a practical identifiability of the corresponding parameter component (Miao et al., 2011; Anane et al., 2019). Nevertheless, no general fixed threshold can be applied since the relative average deviation also depends on the measurement error. Therefore, the assessment relies on the underlying problem and expert. In our study, we considered the histograms of the obtained distributions/samples in order to define an adequate threshold below $20 \%$.

\subsection{Sensitivity analysis of model structure}

The sensitivity of the model simulations based on the input parameter uncertainties was quantified using the change of the maximum viable cell density $X_{\mathrm{v}, \mathrm{max}}$. One model parameter $\theta^{(k)}$ at a time was varied within its previously derived probability distribution (2.2), meanwhile keeping all other parameters constant and computing the resulting target output values (Loucks and Van Beek, 2017). The resulting probability distribution of the target variable was compared to the input probability distribution. This was realized by comparing the relative width of the $80 \%$-intervals of both distributions, $\Delta_{\theta_{i}}$ and $\Delta_{X_{\mathrm{v}, \max }}$, with a quantitative sensitivity coefficient $S$ :

$S=\frac{\Delta_{X_{\mathrm{v} \max }}}{\Delta_{\theta^{(k)}}}$

A parameter was significantly sensitive if $S$ was above $5 \%$.

\subsection{Engineering parameters during scale-up}

All investigated bioreactors were hydrodynamically characterized (Meusel et al., 2016; Kaiser et al., 2015) and engineering parameters were compared with respect to cell growth, metabolism, and product titer during scale-up and in scale-down models (not part of this work). Based on this, a specific power input of $19 \mathrm{~W} \mathrm{~m}^{-3}$ was identified as the scale-up criterion, which was kept constant in this study at all investigated stirred bioreactor scales.

\subsection{Cultivations}

All cultivations considered in this study were performed in single-use bioreactors and are summarized in Table 1, including their scale and cultivation system.

\subsection{Cell line and preculture}

Suspension growing CHO DP-12 cells, producing an Interleukin8 (IgG-1) antibody (clone \#1934, ATCC CRL-12445), were cultivated in this study (provided by Prof. Dr. T. Noll, Bielefeld University, Germany). $1 \mathrm{ml}$ cryo-cultures $\left(1 \cdot 10^{7}\right.$ cells $\mathrm{ml}^{-1}$ ) were thawed and transferred to a $250 \mathrm{ml}$ single-use Erlenmeyer baffled flasks (40 ml working volume, Corning, USA). The used medium was TC-42 (chemically defined, animal component-free, Xell AG, Germany), which was supplemented with $6 \mathrm{mmol} \mathrm{l}^{-1}$ glutamine, $0.1 \mathrm{mg} \cdot \mathrm{l}^{-1}$ LONG R3 IGF-1, and $200 \mathrm{nmol} \mathrm{l}^{-1}$ Methotrexate (all Sigma-Aldrich). The incubators (LT-XC, Kuhner, Switzerland or Multitron cell, Infors $\mathrm{HT}$, Switzerland) were controlled at $37^{\circ} \mathrm{C}, 5 \% \mathrm{CO}_{2}$ (LT-XC) or $7.5 \% \mathrm{CO}_{2}$ (Multitron cell) and $85 \%$ humidity with shaking speeds between $120 \mathrm{rpm}$ (25 mm shaking diameter, Multitron cell) - $200 \mathrm{rpm}$ (12.5 mm shaking diameter, LT-XC). The cells were expanded in shake flasks and no maintenance culture was used.

\subsubsection{Identification of feeding strategy}

The fed-batch strategy was designed in a previous study (see Möller et al., 2019b) using mDoE to reduce the boundary values of an experimental design. There, the proposed method (mDoE) was tested and compared to the fully implemented experimental design with 29 experiments, which were performed in shake flasks ( $30 \mathrm{ml}, 2$ blocks, 14 and 15 parallel experiments). In brief, the incubator (LT-XC, Kuhner) was the same as explained above (2.10) with an increased shaking speed $(220 \mathrm{rpm})$. The feeding design was varied (feed: Chomacs basic feed, Xell AG) with regard to the start times of bolus feeding ( $48 \mathrm{~h}, 72 \mathrm{~h}, 96 \mathrm{~h}$ ), the feeding rate ( $3 \mathrm{ml} \mathrm{d}^{-1}-6 \mathrm{ml} \mathrm{d}^{-1}$ ) and concentrations of glucose (111 mmol $\mathrm{l}^{-1}$ $\left.-222 \mathrm{mmol} \mathrm{l}^{-1}\right)$ and glutamine $\left(9 \mathrm{mmol} \mathrm{l}^{-1}-38 \mathrm{mmol}^{-1}\right)$. In this study, this data was used to estimate the model parameter distributions of the process development scale (shake flasks). Please see (Möller et al., 2019b) for more information.

2.10.2. Process implementation and process validation at $250 \mathrm{ml}$ scale

The formerly identified fed-batch strategy was transferred to the Ambr 250 modular system (Sartorius Stedim Biotech). $0.3 \cdot 10^{6}$ cells $\mathrm{ml}^{-1}$ were inoculated and the starting volume was $200 \mathrm{ml}$. Following feeding (feed as above) steps referring to the 

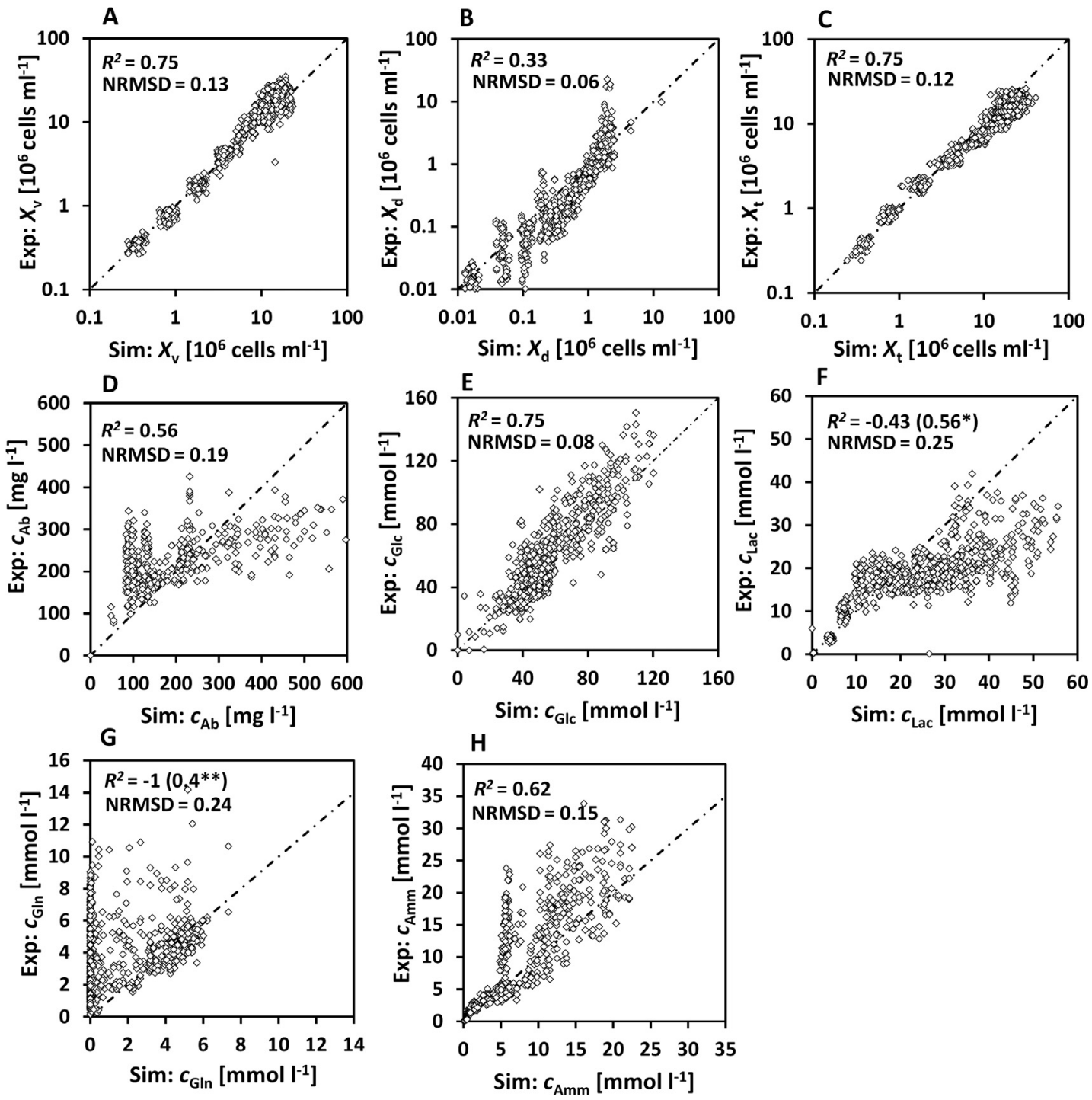

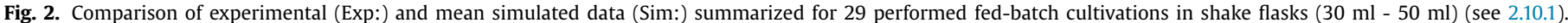
$R^{2}$ reflects goodness of fit against the optimal simulation $(\mathrm{x}=\mathrm{y}) ;{ }^{*}=R^{2}$ for the first $144 \mathrm{~h}$ (lactate formation); ${ }^{* *}=R^{2}$ for the first $96 \mathrm{~h}$.

starting volume were performed: $48 \mathrm{~h}: 2.55 \% ; 72 \mathrm{~h}: 5.1 \%$; $96 \mathrm{~h}$, $120 \mathrm{~h}, 144 \mathrm{~h}: 10.625 \%$. Temperature was set to $37^{\circ} \mathrm{C}$ and headspace aeration to $0.1 \mathrm{vvm}$. Dissolved oxygen was controlled at a minimum of $40 \%$ (submerse sparging with oxygen if needed). $\mathrm{pH}$ was controlled at 7.2 with $\mathrm{CO}_{2}$ submerse sparging. Stirrer speed was adapted to the culture volume, keeping the specific power input of $19 \mathrm{~W} \mathrm{~m}^{-3}$ constant. During the process validation, the starting volume of the bioreactor (previously $200 \mathrm{ml}$ ) was altered to $230 \mathrm{ml}$ $(F=0.5)$ and $170 \mathrm{ml}(F=1.5)$ due to the change in feeding volumes.

\subsubsection{Process scale-up (2 l scale)}

Cells were expanded using $125-500 \mathrm{ml}$ single-use shake flasks (Corning) with 40-160 ml working volume. Starting volume was $1440 \mathrm{ml}$ (UniVessel SU 2L bioreactor, Sartorius Stedim Biotech). The feeding steps were performed based on the starting volume as described above (2.10.2). All process parameters were the same as in Ambr experiments.

\subsubsection{Pilot scale (50 l)}

Cells were expanded using 125-500 ml single-use shake flasks (Corning) with 40-160 ml working volume and a wave-mixed bag with 51 working volume (Cultibag RM 101 basic, Sartorius Stedim
Biotech). For the pilot scale cultivation, the BIOSTAT STR50 (Sartorius Stedim Biotech) was used with 341 starting volume. Feeding was performed as previously described (2.10.2).

\subsection{Analytical methods}

\subsubsection{Identification of feeding strategy}

For the identification of the feeding strategy (TUHH), the cell concentration was determined with the $\mathrm{Z} 2$ particle counter $(\mathrm{Z} 2$, Beckman Coulter, USA) and the viability was measured using the DAPI (4',6-diamidino-2-phenylindole, Sigma-Aldrich) method. Glucose, glutamine, and lactate concentrations were measured with the biochemistry analyzer YSI 2900D (Yellow Springs Instruments, USA). The concentration of ammonium was enzymatically determined with a test kit (AK00091, nzytech, Portugal). The antibody titer was quantified using a high performance liquid chromatographic system (HPLC, Knauer Smartline, Germany) equipped with a Poros-A column (Thermo Fisher Scientific, USA; $0.1 \mathrm{ml}, 4^{\circ} \mathrm{C}$ ). Purified water containing $150 \mathrm{mmol} \mathrm{l}^{-1} \mathrm{NaCl}$ (Sigma-Aldrich) and $50 \mathrm{mmol} \mathrm{l}^{-1} \mathrm{Na}_{2} \mathrm{HPO}_{4}$ ( $\mathrm{pH} 7$, Sigma-Aldrich) was used as the mo-

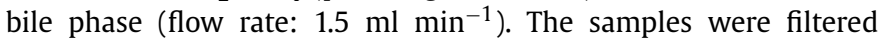
(Cellulose filters, pore size: $0.45 \mu \mathrm{m}$, Restek, Germany) before in- 

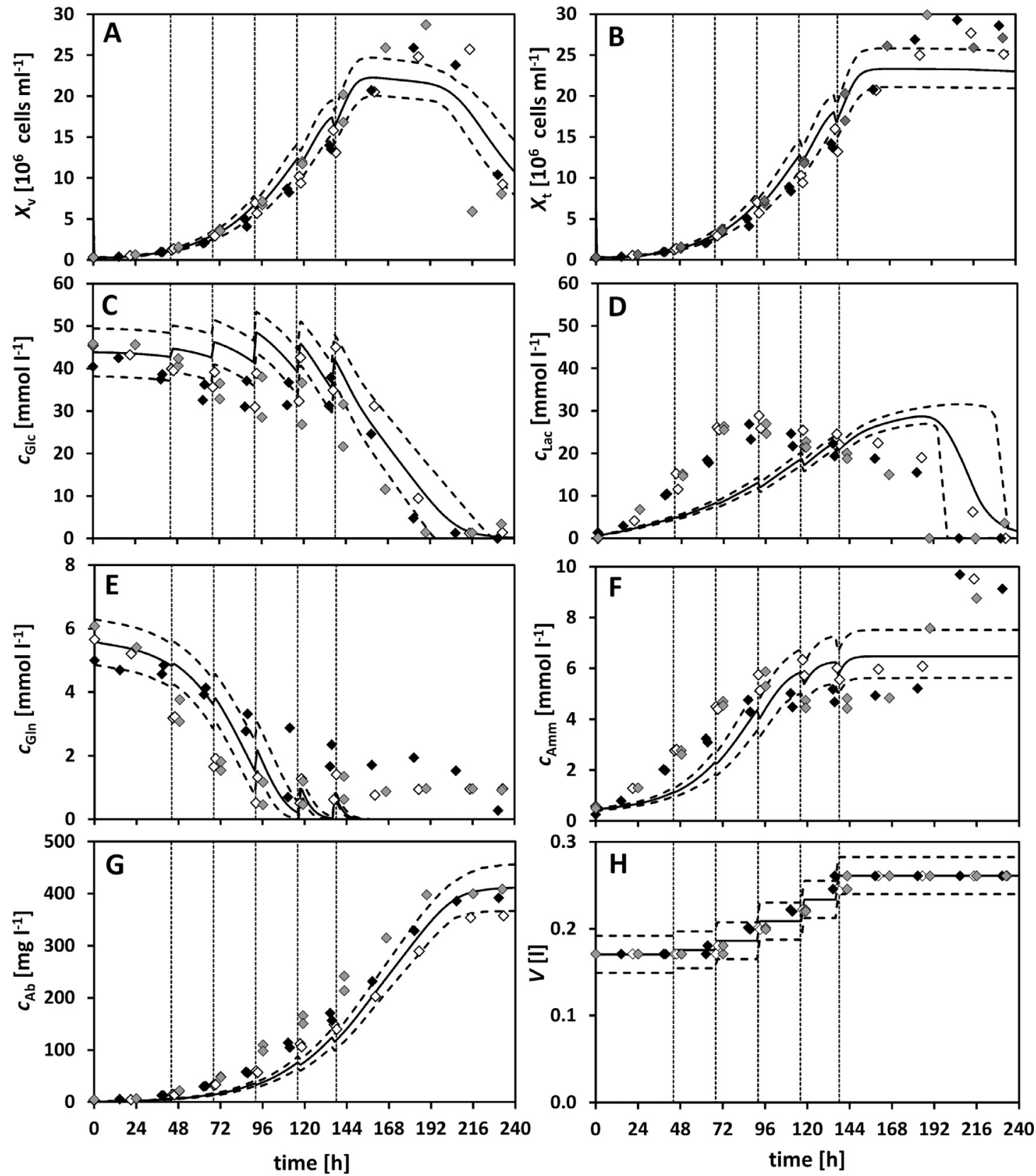

---- Feeding - - -10/90 quantiles _-Mean $\diamond 250 \mathrm{ml} \mathrm{scale} \mathrm{\# 1} \bullet 250 \mathrm{ml}$ scale \#2 $\diamond 250 \mathrm{ml} \mathrm{scale} \mathrm{\# 3}$

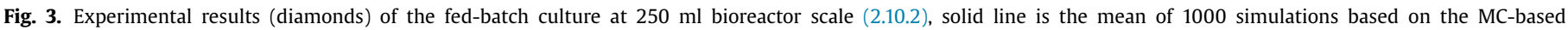
method (see 2.2), dashed line represents the $10 \%$ and $90 \%$ quantiles of the simulations; feeding was performed every $24 \mathrm{~h}$ (pointed line) with a start at $48 \mathrm{~h}$.

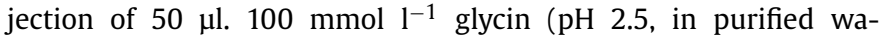
ter, Sigma-Aldrich) was applied to elute the antibody, and the UV signal $(280 \mathrm{~nm})$ was measured. The system was calibrated with a standard curve of diluted Rituximab (Roche, Switzerland), and samples were measured in duplicates.

\subsubsection{Process implementation, re-adjustment, scale-up and pilot} scale

For the experiments in stirred bioreactors (ZHAW), living cell density and viability were measured with the NucleoCounter NC200 (ChemoMetec, Denmark). Glucose, glutamine, lactate, and ammonium were analyzed with the BioProfile 100 Plus (Nova Biomedical, Germany). The antibody was quantified with the Cedex Bio (Roche, Switzerland).

\section{Results and discussion}

This study aims to introduce a model uncertainty-based workflow (see Fig. 1) for the evaluation of the bioprocess dynamics at different scales using model parametric uncertainty quantification and statistical tests. In the beginning, the feeding strategy and the mathematical model of the process development data (shake flask cultures, $30 \mathrm{ml}-50 \mathrm{ml}$ ) is discussed. Then, the feeding strategy was transferred to $250 \mathrm{ml}$ stirred bioreactors and three cultivations were performed. The model parameter distributions were determined and compared between the process development (shake flask) and $250 \mathrm{ml}$ bioreactor scale. Furthermore, scale-up from $250 \mathrm{ml}$ bioprocesses to 21 was statistically validated and the ob- 


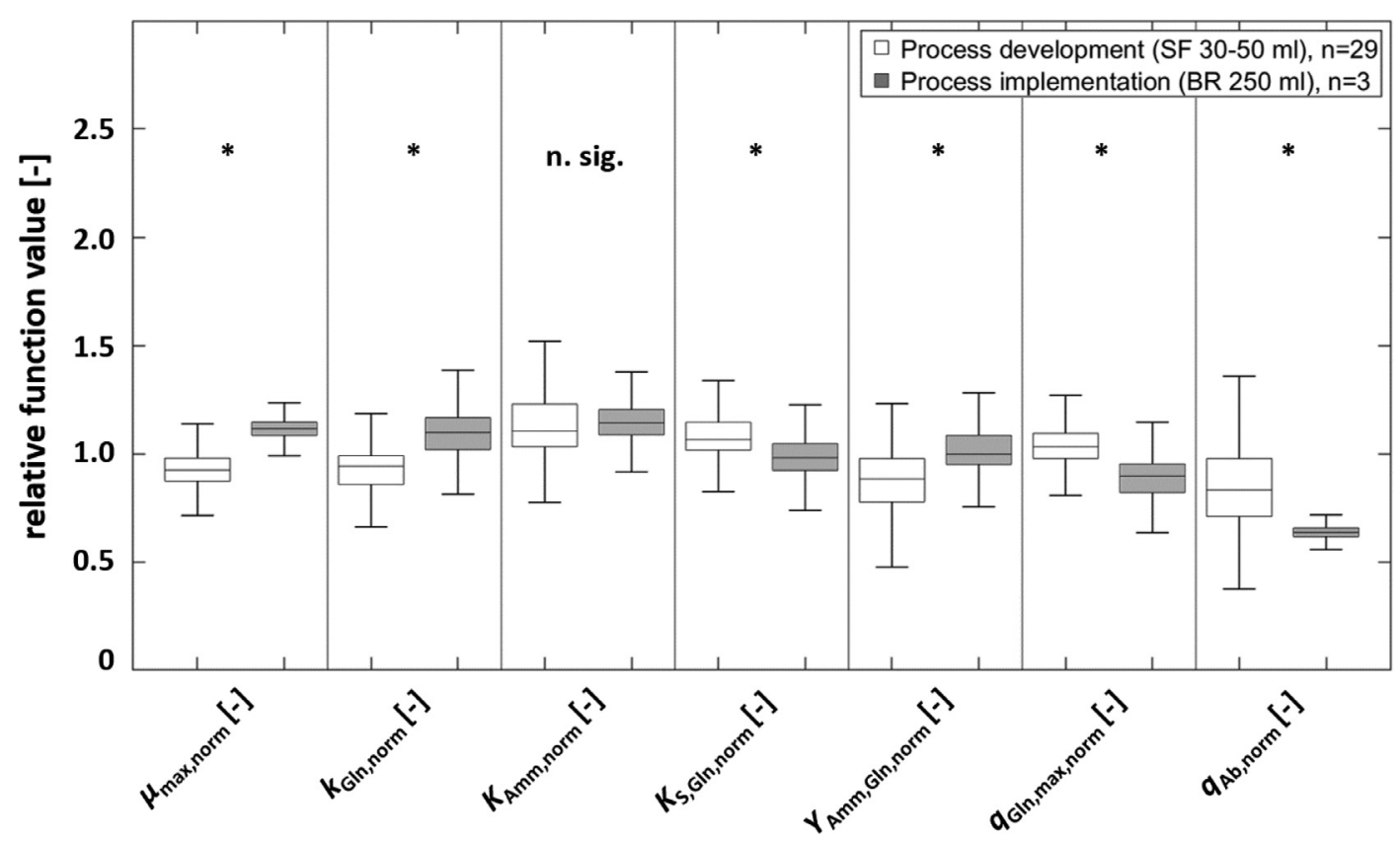

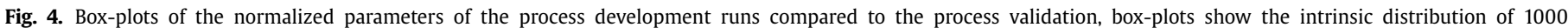

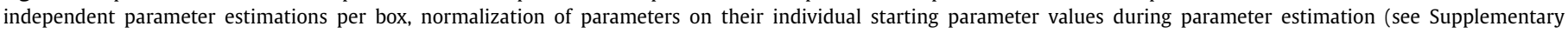
Table 2), ${ }^{*}=$ significant, n. sig. = not significant.

tained parameter distributions (250 $\mathrm{ml}$ and 2 1, respectively) were used to predict the variability of a 501 pilot scale run.

\subsection{Process development ( $30 \mathrm{ml})$ : Identification of fed-batch strategy}

As was described in Möller et al. (2019b), the identified optimal process strategy in shake flask cultivations was: start of bolus feeding after $96 \mathrm{~h}$, glucose concentration in feed $=222 \mathrm{mmol} \mathrm{l}^{-1}$, glutamine concentration in feed $=9 \mathrm{mmol} \mathrm{l}^{-1}$ and a feeding rate of $10 \% \mathrm{v} / \mathrm{v}\left(3 \mathrm{ml} \mathrm{d}^{-1}\right)$. Here, it was aimed to transfer this process strategy from shake flasks to stirred bioreactors and scale the process up to pilot scale. Therefore, it was evaluated that the process dynamics remain constant during scale-up.

\subsubsection{Estimation of model parameters}

668 data points (29 fed-batch cultivations, see 2.10.1) were used as data for the determination of the model parameter distributions (2.2), which are summarized in the Supplementary Figs. 1 - 16. All cultivations were additionally simulated with the mean of the individual parameter distribution and the comparison of the simulated to the measured data is shown in Fig. 2.

The viable (Fig. 2, A), dead (Fig. 2, B) and total cell density (Fig. 2, C) were sufficiently reflected by the average parameter values. The antibody concentration (Fig. 2, D) was simulated with an $R^{2}=0.56$ and NRMSD $=0.19$ and reflects the general relationships, but the maximal antibody concentration was partly over-predicted after $144 \mathrm{~h}$. The modeling of the product formation is widely discussed in literature (Zeng et al., 1998; Pörtner and Schäfer, 1996; Ben Yahia et al., 2015; Möller et al., 2018) and the here modeled constant cell-specific productivity is a rather simple approach, but sufficient for process optimization. Glucose was simulated with high accuracy in all cultivations $\left(R^{2}=0.75, \mathrm{NRMSD}=0.08\right)$, but lactate concentration (Fig. 2, F) was only simulated with high accuracy for the formation of lactate during the first $144 \mathrm{~h}\left(R^{2}=0.56\right.$, indicated by $\left.{ }^{*}\right)$. After that, no further increase in lactate was measured. This is a typical effect in pH-uncontrolled shake flask cultivations (Zhou et al., 2011) and no impact of lactate on cell growth was identified previously for this cell line (Möller et al., 2018;
Table 2

Sensitive model parameters, sensitivity analysis as described in 2.7. *considered significant due to direct linkage to product titer.

\begin{tabular}{ll}
\hline Parameter & $\mathrm{S}[\%]$ \\
\hline$\mu_{\max }$ & $103 \%$ \\
$k_{\mathrm{Gln}}$ & $51 \%$ \\
$k_{\mathrm{Amm}}$ & $27 \%$ \\
$K_{\mathrm{s}, \mathrm{Gln}}$ & $12 \%$ \\
$Y_{\mathrm{Amm}, \mathrm{Gln}}$ & $45 \%$ \\
$q_{\mathrm{Gln}, \max }$ & $44 \%$ \\
$q_{\mathrm{Ab}}^{*}$ & significant \\
\hline
\end{tabular}

2019b). The concentration of glutamine is predicted well if considering only the first $96 \mathrm{~h}$ of cultivation (Fig. 2, G; indicated by $\left.{ }^{* *}\right)$. However, it differs from the simulation towards the end of the cultivation, presumably due to changing $\mathrm{pH}$ and ammonium concentrations (Lüdemann et al., 1994; Ha and Lee, 2014). Cell growth is highly dependent on the glutamine availability and the range of fed glutamine is rather high $\left(9 \mathrm{mmol} \mathrm{l}^{-1}-38 \mathrm{mmol} \mathrm{l}^{-1}\right)$. This leads to a negative $R^{2}$, but an overall acceptable simulation. The concentration of ammonium was predicted with an $R^{2}=0.52$.

Overall, the average model simulations reflect the culture dynamics acceptably for the high amount of data and investigated process strategies in shake flask cultures. Furthermore, the process knowledge is increased throughout the mathematical modeling (Carrondo et al., 2012). The model parameter distributions reflect the parametric uncertainty and the process variability, which are further used to validate the process dynamics during scale-up.

\subsubsection{Identifiability analysis}

Practical identifiability of each parameter was analyzed based on the obtained parameter distribution, interpreting the corresponding histograms as well as the RAD (Miao et al., 2011). Therefore, the histograms of all parameters (see Supplementary Figure 17-20) show high frequencies in the center and low frequencies on the tails on both sides, for which practical identifiability was 


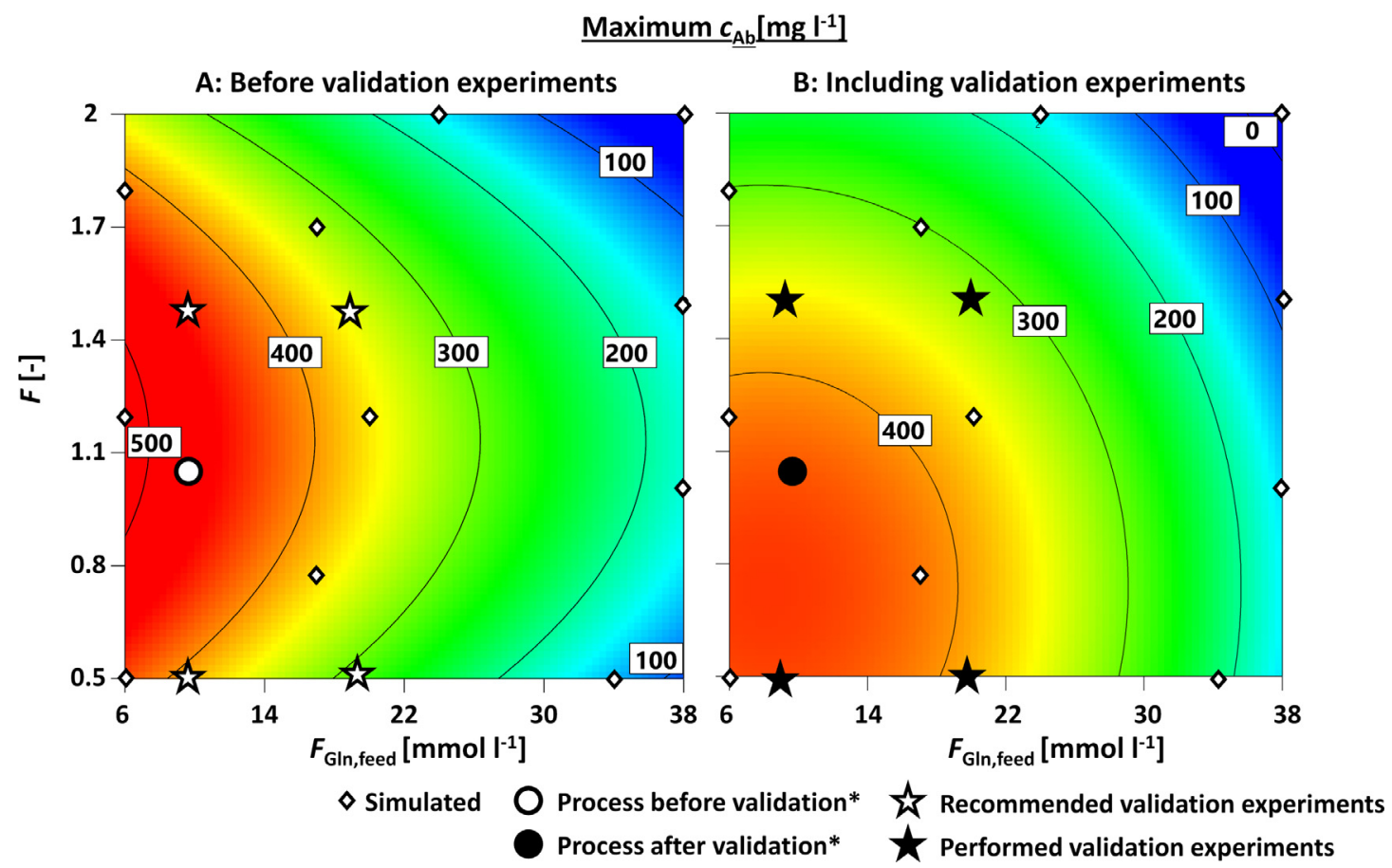

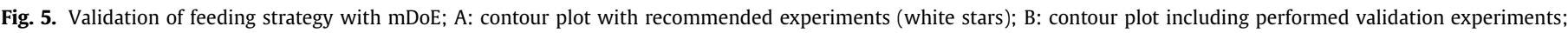
$*=$ experimental data not considered in $\mathrm{mDoE}$.

concluded. This is confirmed by the resulting RAD values, which range from $5 \%-14 \%$.

\subsubsection{Sensitivity analysis}

A sensitivity analysis was performed to reduce the number of adapted and compared parameters to the sensitive ones only (see 2.7). The parameters shown in Table 2 were identified to be sensitive:

$\mu_{\max }$ was identified to be the most sensitive parameter, which is typical in Monod-type models as the main parameter describing $X_{\mathrm{v}}$, which is linked to all differential equations (Supplementary Table 1 ). Moreover, the parameters associated with the glutamine metabolism $\left(q_{\mathrm{Gln}, \max }, k_{\mathrm{Gln}}\right)$ are sensitive because the glutamine concentration, as a main substrate (besides glucose), is also directly linked to cell growth. The inhibitory effect of ammonium is also linked to $X_{\mathrm{v}}$ and the ammonium-related model parameters $Y_{\text {Amm,Gln }}$ and $k_{\text {Amm }}$ are sensitive. The sensitivity of glucose-related model parameters is rather low $\left(k_{\mathrm{S}, \mathrm{Glc}}\right) . q_{\mathrm{Ab}}$ describes the cellspecific antibody production and is sensitive regarding the product formation and was therefore included. Only these parameters were re-adjusted in the following evaluation of the scale-up procedure and for the non-sensitive parameters, the previously determined average values were used (Supplementary Table 3).

\subsection{Transfer from process development to process implementation}

The cell line, the cultivation protocols and the process strategy were transferred to a different research institute (TUHH to ZHAW), comparable to a tech transfer from research and development to process implementation and scale-up. In the beginning, the process strategy was scaled up to a stirred bioreactor system (see 2.10.2, working volume: $250 \mathrm{ml}$ ) for verification experiments. The formerly determined feeding strategy was slightly adapted due to practical bioreactor handling and to ensure process robustness. Therefore, the glucose concentration in the feed was previously identified to have only a low impact on the bioprocess (Möller et al., 2019b) and was changed to $111 \mathrm{mmol} \mathrm{l}^{-1}$ to avoid overfeeding. The glutamine concentration in the feed was $9 \mathrm{mmol}^{-1}$ and the feeding rate slightly resembled an exponential-like feeding (see 2.10.2).

\subsubsection{MC-Based uncertainty quantification}

Three test runs were performed with the transferred and scaled up process strategy (stirred bioreactors, $250 \mathrm{ml}$ ) and the model parameters were estimated using the MC-based method (2.2). The experimental data and the model simulations including the parametric uncertainty-based prediction bands are shown in Fig. 3.

The exponential growth phase was simulated well for the viable (see Fig. $3 \mathrm{~A}$ ) and total cell density (Fig. 3 B) starting with approx. $0.3 \cdot 10^{6}$ cells $\mathrm{ml}^{-1}$ until a final concentration of $22 \cdot 10^{6}$ cells $\mathrm{ml}^{-1}$ (168 h). In general, further cell growth in the stationary phase progressed with reduced cell volume, limitations, and inhibitory effects (Zeng et al., 1998). This was only partly included in the model and the maximal cell concentrations $\left(X_{\mathrm{v}}, X_{\mathrm{t}}\right)$ were therefore slightly underestimated in the stationary phase. The glucose concentration (Fig. $3 \mathrm{C}$ ) was well predicted by the model including the feed pulses and the late glucose consumption after the last feed pulse $(t>138 \mathrm{~h}$ ). The lactate concentration (Fig. $3 \mathrm{D}$ ) was predicted with variations during lactate formation but the time and course of lactate uptake was predicted sufficiently. The lactate metabolism with metabolic dysfunctions (known as "Warburgeffect") including high formation rates at the beginning of the cultivation, followed by a stagnation of lactate accumulation, and the switch to lactate uptake is still investigated in research (Hartley et al., 2018; Ulonska et al., 2018; Zalai et al., 2015). As an example, Hartley et al. (2018) reviewed current theories (e.g., pH, pyruvate availability, mitochondrial function) regarding the lactate metabolism, and hypothesized that lactate consumption is a function of the cellular redox state (Hartley et al., 2018). For the here aimed computational evaluation of process strategies during scaleup, a kinetic description of cell growth and metabolism was targeted and the prediction of the lactate dynamics is therefore seen sufficient. Glutamine (Fig. 3 E) and ammonium (Fig. 3 F) were simulated accordingly with the experimental data and the antibody 

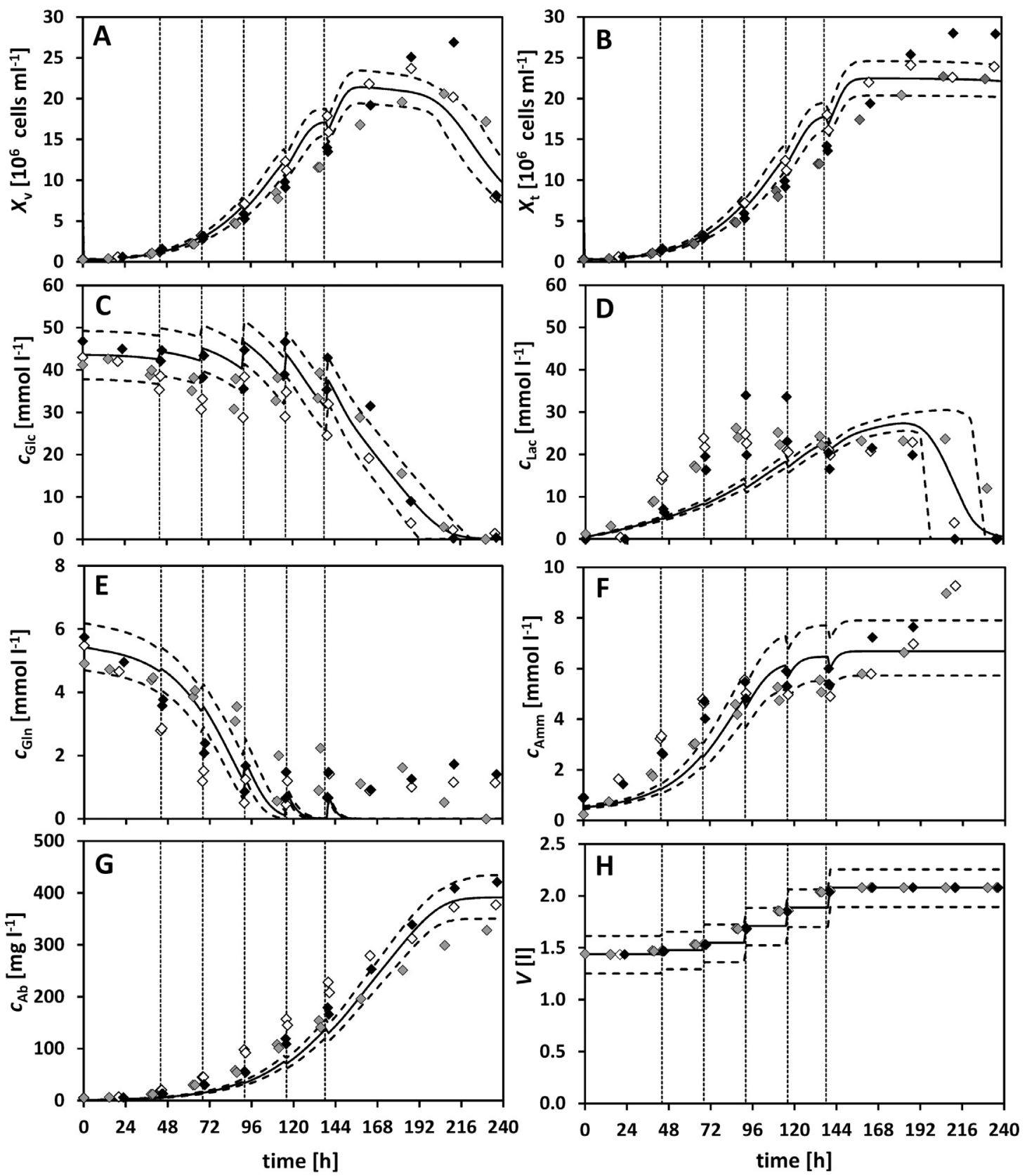

-.---.-Feeding - - -10/90 quantiles - Mean

$\diamond 2$ I scale \#1 $\bullet 2$ I scale \#2 $\diamond$ I scale \#3

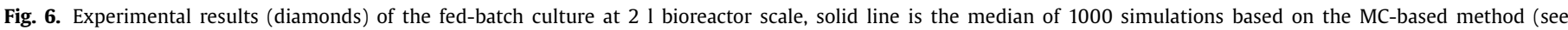
2.2), dashed line represents the $10 \%$ and $90 \%$ quantiles of the simulations; feeding was performed every 24 h (pointed line) with a start at 48 h.

concentration (Fig. $3 \mathrm{G}$ ) increased constantly up to $387 \pm 16 \mathrm{mg} \mathrm{l}^{-1}$ (average of $216 \mathrm{~h}$ and $240 \mathrm{~h}$ ), which was also simulated. The volume (Fig. $3 \mathrm{H}$ ) was simulated as measured. $R^{2}$ and NRMSD are shown in Supplementary Table 4. Overall, the simulations are in good agreement with the experimental data and the model reflects the bioprocess dynamics sufficiently. A description of the mechanistic links using a mathematical process model is the basis of the proposed concept and an appropriate description of the bioprocess needs to be ensured if the workflow is applied to a different cell line or process.

\subsubsection{Statistical comparison of parameter distributions}

As proposed in the parametric uncertainty-based workflow (Fig. 1, box 3), the means of the parameter distributions are sta- tistically compared to evaluate if the dynamics of the bioprocess changed (Fig. 4). The mean parameter values are listed in Supplementary Table 3.

An increase of $23 \%$ was determined in the mean of $\mu_{\text {max,norm, }}$ which shows a higher cell growth in $\mathrm{pH}$ and $\mathrm{pO}_{2}$ controlled bioreactors. Moreover, the glutamine-dependent model parameters differ significantly between both scales thus indicating an average lower maximal uptake rate $\left(q_{\mathrm{Gln} \text {,max,norm }}\right)$ and a different affinity to the glutamine availability $\left(k_{\mathrm{Gln}, \mathrm{norm}}, K_{\mathrm{s}, \mathrm{Gln}, \text { norm }}\right)$. The same trend was identified for $Y_{\mathrm{Amm}, \mathrm{Gln} \text {,norm }}$ with a higher ammonium formation in the bioreactor experiments compared to the shake flask cultivations. The dissociation of $\mathrm{NH}_{3}$ to $\mathrm{NH}_{4}$ is affected by the $\mathrm{pH}$, thus explaining different ammonium concentrations in the controlled bioreactor experiments compared to the shake flask cul- 


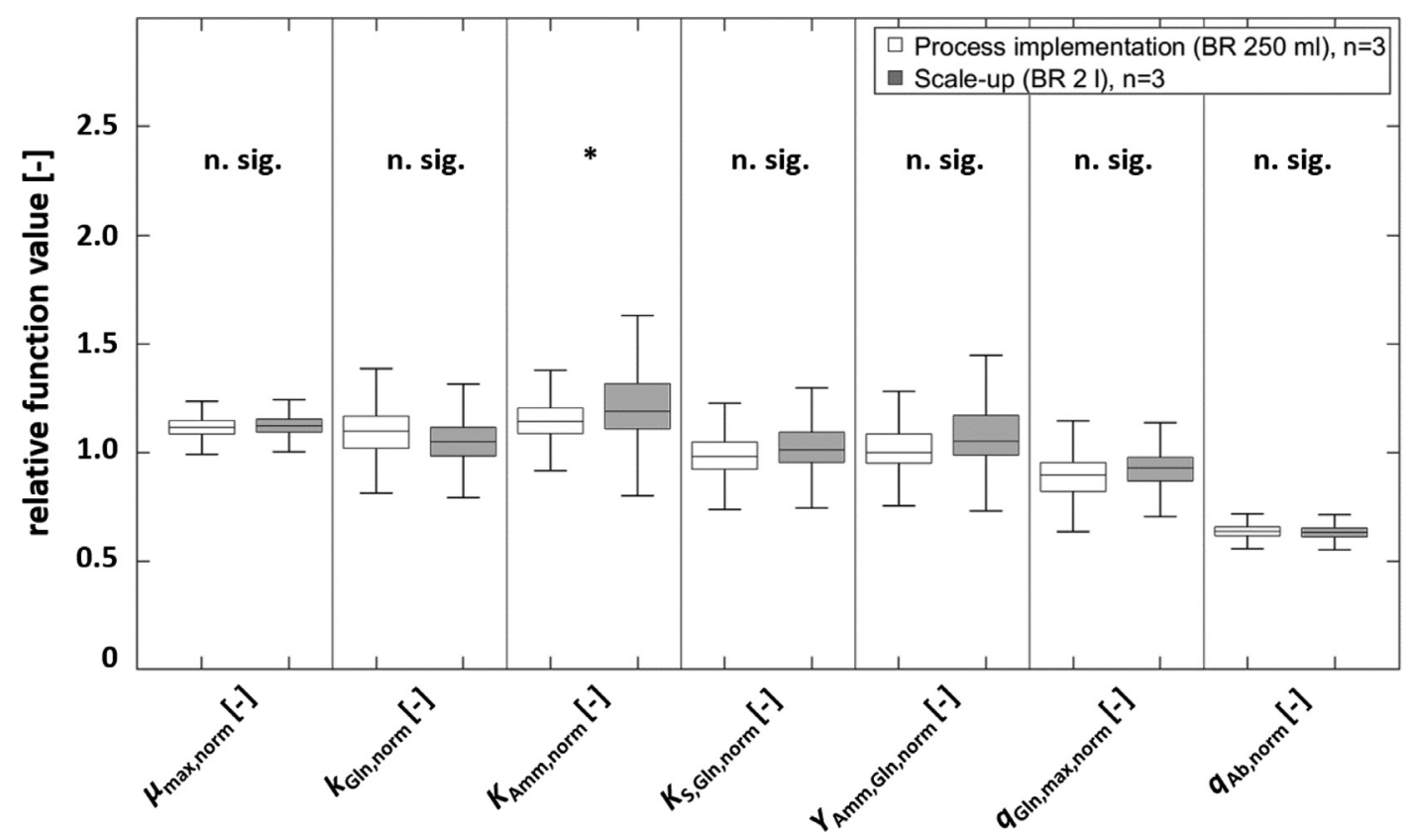

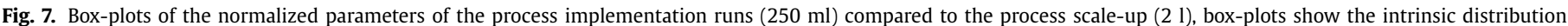

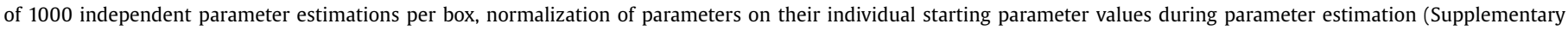
Table 2), ${ }^{*}=$ significant, $\mathrm{n}$. sig. = not significant.

tures (Lüdemann et al., 1994). $q_{\mathrm{Ab} \text {,norm }}$ was widely distributed in the shake flask cultivation, which indicates its correlation to the different investigated feeding strategies. The width of the whiskers was narrower in the bioreactor runs and the mean $q_{\mathrm{Ab}, \text { norm }}$ was reduced in the transferred process. However, the overall process titer was comparable in both scales due to a higher viable cell density in the bioreactor cultivations. The means of $K_{\mathrm{Amm} \text {,norm }}$ were not significantly different between both scales.

In summary, differences in the dynamics of the growth and metabolism could be statistically identified for the transfer from process development (shake flask) to process implementation scale (stirred bioreactor). Moreover, these differences could be quantified and actions could be recommended based on the proposed workflow. Therefore, a re-validation of the formerly determined process strategy was recommended to ensure that the targeted design space (i.e. process strategy) is still met (Fig. 1, box 4).

\subsection{Validation of process strategy}

The validation of the formerly determined process strategy during process implementation was performed using $\mathrm{mDoE}$ (Möller et al., 2019b). Therefore, the glutamine concentration in the feed $\left(F_{\mathrm{Gln} \text {,feed }}\right)$ and the relative feeding rate ( $F_{\text {Rate }} \cdot F=$ $F_{\text {Rate,experimental }}$ ) were defined as experimental factors. As an example, if $F$ is defined as two, it means that all feed pulses ( $F_{\text {Rate,experimental }}$, see 2.10 .2 ) were doubled. Validation cultivations were planned using an I-optimal DoE design mode (16 recommended experiments). The planned cultivations were simulated using the model (mean model parameters as in 3.2.2) and the maximal antibody concentration was defined as response. A quadratic response surface model (RSM) was estimated (Design Expert 11) and the contour plot is seen in Fig. $5 \mathrm{~A}$.

The current process settings (Fig. $5 \mathrm{~A}$ ) were at the maximal achievable antibody concentrations within a flat area, which reflects a stable point of operation. To validate the process strategy and to ensure process stability, four validation experiments were planned (white stars Fig. $5 \mathrm{~A}$ ). It was aimed to ensure the stabil- ity of the process and to identify the shape of the maximum. The validation cultivations were experimentally performed and the experimental settings were included with their respective maximum antibody concentrations as design points in the DoE (Fig. 5 B). The shape of the maximal antibody concentration slightly changed with an optimal area between the performed validation cultivations, without harsh boundaries, and a flat area. The process stability could, therefore, be ensured and the formerly defined process (Fig. $5 \mathrm{~A} / \mathrm{B}$ ) was not changed. The main advantage of using $\mathrm{mDoE}$ here is that the stability of the process could be validated for the quantified changes in the process dynamics throughout the model parameter uncertainty determination.

\subsection{Scale-up from $250 \mathrm{ml}$ to $2 \mathrm{l}$}

The implemented and validated process strategy was scaled up to 21 scale, with the same hydrodynamics as at the $250 \mathrm{ml}$ scale (see 2.10.3). Three test runs were performed and the scale-up was evaluated as proposed in the workflow (Fig. 1). Therefore, the model parameter distributions of the 21 bioreactor experiments were estimated using the MC-based method (2.2) and statistically compared to the $250 \mathrm{ml}$ scale.

\subsubsection{MC-based uncertainty quantification}

The model-based simulations, with $10 \%$ and $90 \%$ quantiles of simulation and the experimental data, are shown in Fig. 6 .

Overall, the model predictions of the process at the 21 (Fig. 6) scale were comparable to the process implementation at $250 \mathrm{ml}$ scale (Fig. 3). Differences in $R^{2}$ and NRMSD (see Supplementary Table 5) were low.

\subsubsection{Statistical comparison of parameter distributions}

The dynamics of the process were quantified with the statistical comparison of the parameter distributions (Fig. 7). The means of the parameter distributions are shown in Supplementary Table 2.

$\mu_{\text {max,norm }}, k_{\mathrm{Gln}, \mathrm{norm}}, K_{\mathrm{s}, \mathrm{Gln}, \mathrm{norm}}, Y_{\mathrm{Amm}, \mathrm{Gln}, \mathrm{norm}}, q_{\mathrm{Gln} \text {,max,norm }}$, and $q_{\mathrm{Ab}, \text { norm }}$ were identified to be not significantly different on a $5 \%$ 

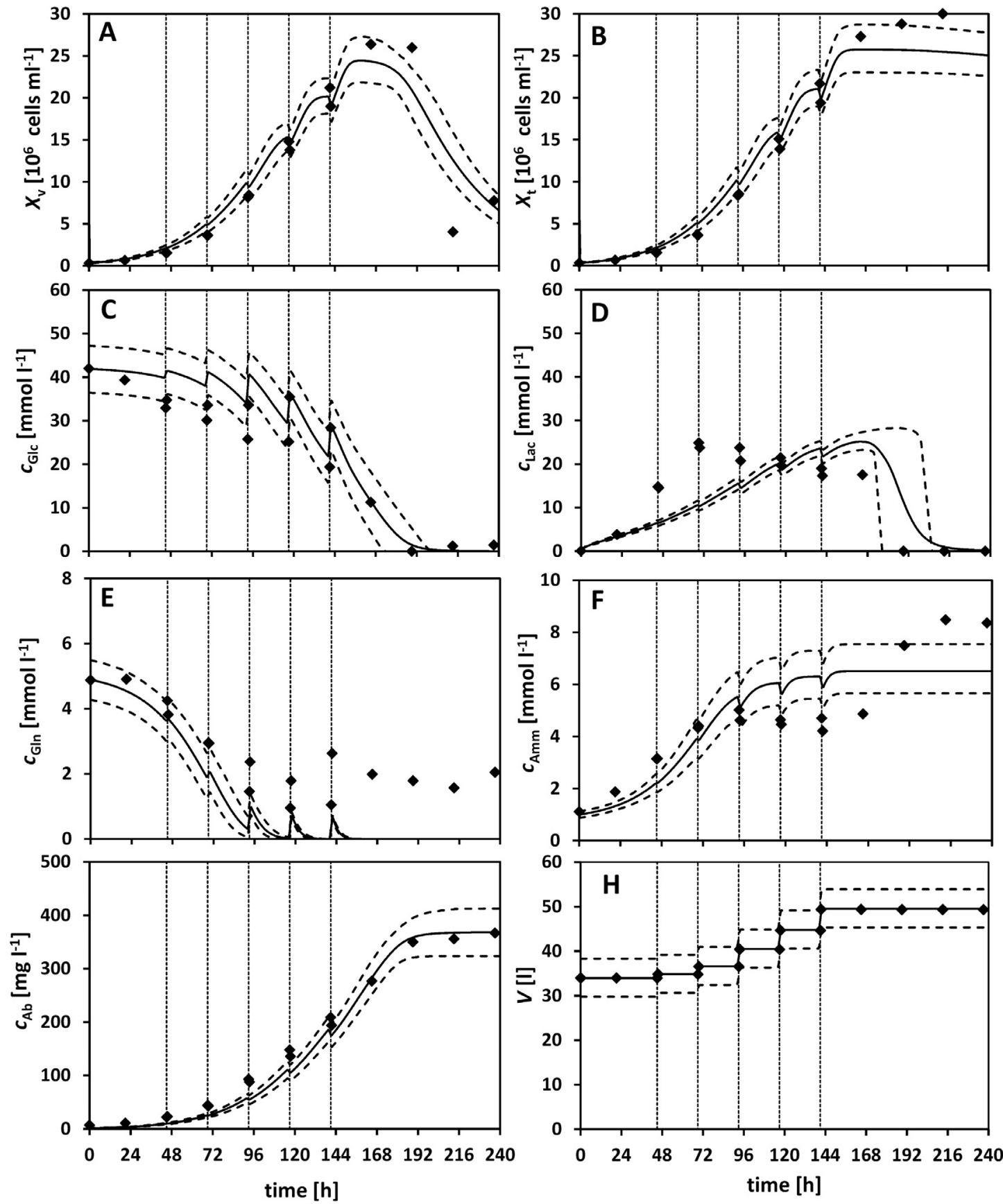

------ Feeding - - -Predicted 10/90 quantiles

-Mean

- Pilot scale (50 I)

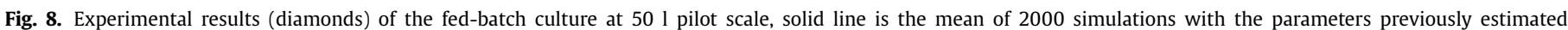

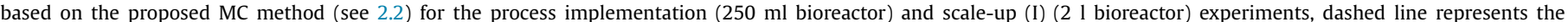
$10 \%$ and $90 \%$ quantiles of the simulations; feeding was performed every $24 \mathrm{~h}$ (pointed line) with a start at $48 \mathrm{~h}$.

significance level. $K_{\text {Amm,norm }}$ was slightly higher in the scaled up process than during the process implementation runs $(250 \mathrm{ml})$, but no differences were present in the maximal ammonium concentration and this change was therefore neglected. In summary, the process dynamics remain stable during the scale-up from process implementation to process scale-up.

In conventional scale-up studies, the pure cultivation data of both scales ( $250 \mathrm{ml}$ and 21 , respectively) would have been compared and a heuristic decision of the goodness of scale-up would have been drawn (e.g. same maximal titer, trends) (Rameez et al., 2014; Li et al., 2013). In the proposed workflow, the model uncertainty is quantified based on the available experimental variabil- ity and measurement error. Therefore, the process variability is determined on a timely axis (10\% and $90 \%$ quantiles of simulation, Fig. 6) and in the parameter distributions (Fig. 7). This enables a knowledge-driven decision-making routine based on the process dynamics with the incorporation of the available data in the process model. In accordance with the proposed workflow (Fig. 1, 3) scale-up has proceeded with the confirmed process strategy.

\subsection{Scale-up to $50 \mathrm{l}$ pilot scale}

The process strategy was further scaled up to 501 pilot scale and one verification cultivation was performed. In general, the 
quantification of the model parameter distributions requires multiple cultivation runs (i.e. 3), which were not available for the pilot scale. Therefore, the formerly determined parameter distributions (250 $\mathrm{ml}$ and $2 \mathrm{l}$, respectively) were used to predict the expected process variability of the pilot scale run a priori, as shown in Fig. 8.

The simulated mean and the $10 \%$ and $90 \%$ quantiles are in good alignment with the experimental data. The antibody concentration (Fig. $8 \mathrm{G}$ ) increased constantly up to $367 \mathrm{mg} \mathrm{l}^{-1}$ and is comparable to the formerly performed processes in smaller scales and other studies with the same cell line (Möller et al., 2019a, 2019b). The main advantage of predicting the $10 \%$ and $90 \%$ quantiles of the pilot scale based on the previously determined parameter distributions is that the experimental variability is incorporated, even if the process knowledge was gained at smaller scales (Hernández Rodríguez et al., 2019; Xing et al., 2010). Furthermore, the a priori simulation of the scaled up process and its comparison with newly available data at the respective scale can be used to prove the current process understanding. Differences between the data and simulations could assist in the identification of variations in so far not targeted scale-up parameters, even if they were not modeled (Brunner et al., 2017; Narayanan et al., 2019). In summary, the process strategy was successfully scaled up to $50 \mathrm{l}$ pilot scale and the formerly obtained knowledge was considered with the prediction of the $10 \%$ and $90 \%$ quantiles.

\section{Conclusion}

A workflow for a knowledge-driven computational evaluation of the process strategy during scale-up was introduced. Therefore, the process dynamics are described by a mathematical process model and the model parameters are represented as probability functions, which are determined based on the experimental variability. The probability functions derived at different scales are then statistically compared to identify changes in the bioprocess dynamics and validation of the process strategy is recommended if the dynamics are significantly different. Otherwise, scale-up can proceed, and the process strategy is to be considered sufficient. This workflow was discussed on the scale-up of a CHO DP-12 fed-batch process, which was successfully scaled up to 501 pilot scale. The introduced approach provides a novel, knowledge-driven decision-making tool for bioprocess development and implementation. Further studies will focus on the automated re-design of process strategies with the consideration of the process model during scale-up and the combination of computational fluid dynamics with the process model.

\section{Author Contribution Statement}

All authors contributed to the paper.

\section{Declaration of Competing Interests}

The authors declare that they have no known competing financial interests or personal relationships that could have appeared to influence the work reported in this paper.

The authors declare the following financial interests/personal relationships which may be considered as potential competing interests:

\section{Acknowledgment}

Funding: This study was partially funded by the German Federal Ministry of Education and Research (BMBF, Grant 031B0305 and 031B0577A). Connflict of interests: The authors declare that there are no conflicts of interest. Special thanks: We kindly thank Krathika Bhat for English proof reading.

\section{Supplementary material}

Supplementary material associated with this article can be found, in the online version, at 10.1016/j.compchemeng.2019. 106693

\section{References}

Abt, V., Barz, T., Cruz-Bournazou, M.N., Herwig, C., Kroll, P., Möller, J., Pörtner, R. Schenkendorf, R., 2018. Model-based tools for optimal experiments in bioprocess engineering. Curr. Opin. Chem. Eng. 22, 244-252. doi:10.1016/j.coche.2018. 11.007.

Alsayyari, A.A., Pan, X., Dalm, C., van der Veen, J.W., Vriezen, N., Hageman, J.A., Wijffels, R.H., Martens, D.E., 2018. Transcriptome analysis for the scale-down of a CHOcell fed-batch process. J. Biotechnol. 279, 61-72. doi:10.1016/j.jbiotec.2018. 05.012.

Anane, E., C, D.C.L., Barz, T., Sin, G., Gernaey, K.V., Neubauer, P., Bournazou, M.N.C., 2019. Output uncertainty of dynamic growth models: effect of uncertain parameter estimates on model reliability. Biochem. Eng. J. 150, 107247. doi:10.1016/j. bej.2019.107247.

Ben Yahia, B., Malphettes, L., Heinzle, E., 2015. Macroscopic modeling of mammalian cell growth and metabolism. Appl. Microbiol. Biotechnol. 99 (17), 7009-7024. doi:10.1007/s00253-015-6743-6.

Brunner, M., Fricke, J., Kroll, P., Herwig, C., 2017. Investigation of the interactions of critical scale-up parameters (ph, po2 and pco2) on CHO batch performance and critical quality attributes. Bioprocess Biosyst. Eng. 40 (2), 251-263. doi:10.1007/ s00449-016-1693-7.

Carrondo, M.J.T., Alves, P.M., Carinhas, N., Glassey, J., Hesse, F., Merten, O.-W., Micheletti, M., Noll, T., Oliveira, R., Reichl, U., Staby, A., Teixeira, A.P., Weichert, H., Mandenius, C.-F., 2012. How can measurement, monitoring, modeling and control advance cell culture in industrial biotechnology? Biotechnol. J. 7 (12), 1522-1529. doi:10.1002/biot.201200226.

Catapano, G., Czermak, P., Eibl, R., Eibl, D., Pörtner, R., 2009. Bioreactor Design and Scale-Up. Springer Berlin Heidelberg, Berlin, Heidelberg, pp. 173-259.

Gmeiner, C., Saadati, A., Maresch, D., Stanimira, K., Frank, M., Altmann, F., Herwig, C., Spadiut, O., 2015. Development of a fed-batch process for a recombinant pichia pastoris och1 strain expressing a plant peroxidase. Microb. Cell Fact. 14, 1. doi:10.1186/s12934-014-0183-3.

Guideline, I.H.T., 2009. Pharmaceutical development. Q8 (2R). As revised in August.

Ha, T.K., Lee, G.M., 2014. Effect of glutamine substitution by tca cycle intermediates on the production and sialylation of fc-fusion protein in chinese hamster ovary cell culture. J. Biotechnol. 180, 23-29. doi:10.1016/j.jbiotec.2014.04.002.

Hartley, F., Walker, T., Chung, V., Morten, K., 2018. Mechanisms driving the lactate switch in chinese hamster ovary cells. Biotechnol. Bioeng. 115 (8), 1890-1903. doi:10.1002/bit.26603.

Hernández Rodríguez, T., Posch, C., Schmutzhard, J., Stettner, J., Weihs, C., Pörtner, R., Frahm, B., 2019. Predicting industrial-scale cell culture seed trains-A Bayesian framework for model fitting and parameter estimation, dealing with uncertainty in measurements and model parameters, applied to a nonlinear kinetic cell culture model, using an MCMC method. Biotechnol. Bioeng. 116 (11), 2944-2959. doi:10.1002/bit.27125.

Herwig, C., Garcia-Aponte, O.F., Golabgir, A., Rathore, A.S., 2015. Knowledge management in the qbd paradigm: manufacturing of biotech therapeutics. Trends Biotechnol. 33 (7), 381-387. doi:10.1016/j.tibtech.2015.04.004.

Ivarsson, M., Noh, H., Morbidelli, M., Soos, M., 2015. Insights into ph-induced metabolic switch by flux balance analysis. Biotechnol. Prog. 31 (2), 347-357. doi:10.1002/btpr.2043.

Ju, L.-K., Chase, G., 1992. Improved scale-up strategies of bioreactors. Bioprocess. Eng. 8 (1-2), 49-53.

Kaiser, S.C., Eibl, R., Eibl, D., 2011. Engineering characteristics of a single-use stirred bioreactor at bench-scale: the mobius cellready 31 bioreactor as a case study. Eng. Life Sci. 11 (4), 359-368. doi:10.1002/elsc.201000171.

Kaiser, S.C., Kraume, M., Eibl, D., Eibl, R., 2015. Single-use bioreactors for animal and human cells. In: Animal Cell Culture. Springer, pp. 445-500.

Kern, S., Platas-Barradas, O., Pörtner, R., Frahm, B., 2016. Model-based strategy for cell culture seed train layout verified at lab scale. Cytotechnology 68 (4), 10191032. doi:10.1007/s10616-015-9858-9.

Klöckner, W., Tissot, S., Wurm, F., Büchs, J., 2012. Power input correlation to characterize the hydrodynamics of cylindrical orbitally shaken bioreactors. Biochem. Eng. J. 65, 63-69. doi:10.1016/j.bej.2012.04.007.

Kuchemüller, K.B., Pörtner, R., Möller, J., 2020. Efficient Optimization of Process Strategies with Model-Assisted Design of Experiments. Animal Cell Biotechnology doi:10.1007/978-1-0716-0191-4_13.

Langford, E., 2006. Quartiles in elementary statistics. J. Stat. Educat. 14 (3), null. doi:10.1080/10691898.2006.11910589.

Legmann, R., Schreyer, H.B., Combs, R.G., McCormick, E.L., Russo, A.P., Rodgers, S.T., 2009. A predictive high-throughput scale-down model of monoclonal antibody production in CHO cells. Biotechnol. Bioeng. 104 (6), 1107-1120. doi:10.1002/bit. 22474.

Li, F., Shen, A., Amanullah, A., 2013. Cell Culture Processes in Monoclonal Antibody Production. American Cancer Society, pp. 1-38.

Liu, Y., Gunawan, R., 2017. Bioprocess optimization under uncertainty using ensemble modeling. J. Biotechnol. 244, 34-44. doi:10.1016/j.jbiotec.2017.01.013. 
Loucks, D.P., Van Beek, E., 2017. Water Resource Systems Planning and Management: An Introduction to Methods, Models, and Applications. Springer.

Lüdemann, I., Pörtner, R., Märkl, H., 1994. Effect of nh3 on the cell growth of a hybridoma cell line. Cytotechnology 14 (1), 11-20. doi:10.1007/BF00772191.

Meusel, W., Löffelholz, C., Husemann, U., Dreher, T., Greller, G., Kauling, J., 2016. Recommendations for process engineering characterisation of single-use bioreactors and mixing systems by using experimental methods. DECHEMA

Miao, H., Xia, X., Perelson, A.S., Wu, H., 2011. On identifiability of nonlinear ode models and applications in viral dynamics. SIAM Rev. 53 (1), 3-39.

Möller, J. Bhat, K. Riecken, K. Pörtner, R., Zeng A.-P., Jandt, U., 2019. Processinduced cell cycle oscillations in CHO cultures: online monitoring and modelbased investigation. Biotechnol. Bioeng. 116 (11), 2931-2943. doi:10.1002/bit 27124.

Möller, J., Korte, K., Pörtner, R., Zeng, A.-P., Jandt, U., 2018. Model-based identification of cell-cycle-dependent metabolism and putative autocrine effects in antibody producing CHO cell culture. Biotechnol. Bioeng. 115 (12), 2996-3008. doi:10.1002/bit.26828.

Möller, J., Kuchemüller, K.B., Steinmetz, T., Koopmann, K.S., Pörtner, R., 2019. Modelassisted design of experiments as a concept for knowledge-based bioprocess development. Bioprocess Biosyst. Eng. doi:10.1007/s00449-019-02089-7.

Narayanan, H., Luna, M.F., von Stosch, M., Cruz Bournazou, M.N., Polotti, G., Morbidelli, M., Butte, A., Sokolov, M., 2019. Bioprocessing in the digital age: the role of process models. Biotechnol. J. doi:10.1002/biot.201900172.

Nelder, J.A., Mead, R., 1965. A simplex method for function minimization. Comput. J. 7 (4), 308-313.

Neunstoecklin, B., Stettler, M., Solacroup, T., Broly, H., Morbidelli, M., Soos, M., 2015. Determination of the maximum operating range of hydrodynamic stress in mammalian cell culture. J. Biotechnol. 194, 100-109. doi:10.1016/j.jbiotec.2014. 12.003 .

Nienow, A.W., Langheinrich, C., Stevenson, N.C., Emery, A.N., Clayton, T.M., Slater, N.K.H., 1996. Homogenisation and oxygen transfer rates in large agitated and sparged animal cell bioreactors: some implications for growth and production. Cytotechnology 22 (1), 87-94. doi:10.1007/BF00353927.

Nienow, A.W., Rielly, C.D., Brosnan, K., Bargh, N., Lee, K., Coopman, K., Hewitt, C.J. 2013. The physical characterisation of a microscale parallel bioreactor platform with an industrial $\mathrm{CHO}$ cell line expressing an igg4. Biochem. Eng. J. 76, 25-36. doi:10.1016/j.bej.2013.04.011.

Pörtner, R., Schäfer, T., 1996. Modelling hybridoma cell growth and metabolism - a comparison of selected models and data. J. Biotechnol. 49 (2), 119-135. doi:10. 1016/0168-1656(96)01535-0.

Rameez, S., Mostafa, S.S., Miller, C., Shukla, A.A., 2014. High-throughput miniaturized bioreactors for cell culture process development: reproducibility, scalability, and control. Biotechnol. Prog. 30 (3), 718-727. doi:10.1002/btpr.1874.

Rosseburg, A., Fitschen, J., Wutz, J., Wucherpfennig, T., Schlüter, M., 2018. Hydrodynamic inhomogeneities in large scale stirred tanks influence on mixing time. Chem. Eng. Sci. 188, 208-220. doi:10.1016/j.ces.2018.05.008.

Rouiller, Y., Périlleux, A., Vesin, M.-N., Stettler, M., Jordan, M., Broly, H., 2014. Modulation of mab quality attributes using microliter scale fed-batch cultures. Biotechnol. Prog. 30, 571-583. doi:10.1002/btpr.1921.
Sharma, C., Malhotra, D., Rathore, A.S., 2011. Review of computational fluid dynamics applications in biotechnology processes. Biotechnol. Prog. 27 (6), 1497-1510. doi:10.1002/btpr.689.

Sieck, J.B., Cordes, T., Budach, W.E., Rhiel, M.H., Suemeghy, Z., Leist, C., Villiger, T.K. Morbidelli, M., Soos, M., 2013. Development of a scale-down model of hydrodynamic stress to study the performance of an industrial $\mathrm{CHO}$ cell line under simulated production scale bioreactor conditions. J. Biotechnol. 164 (1), 41-49. doi:10.1016/j.jbiotec.2012.11.012.

Sin, G., Gernaey, K.V., Lantz, A.E., 2009. Good modeling practice for PAT applications: propagation of input uncertainty and sensitivity analysis. Biotechnol. Prog. 25 (4), 1043-1053. doi:10.1002/btpr.166.

Singer, S., Singer, S., 2004. Efficient implementation of the Nelder-Mead search algorithm. Appl. Numer. Anal. Comput. Math. 1 (2), 524-534. doi:10.1002/anac. 200410015.

Torkashvand, F., Vaziri, B., Maleknia, S., Heydari, A., Vossoughi, M., Davami, F., Mahboudi, F., 2015. Designed amino acid feed in improvement of production and quality targets of a therapeutic monoclonal antibody. PLoS ONE 10, 1-21. doi:10.1371/journal.pone.0140597.

Ulonska, S., Kroll, P., Fricke, J., Clemens, C., Voges, R., Müller, M.M., Herwig, C., 2018. Workflow for target-oriented parametrization of an enhanced mechanistic cell culture model. Biotechnol. J. 13 (4), 1700395. doi:10.1002/biot.201700395.

Varley, J., Birch, J., 1999. Reactor design for large scale suspension animal cell culture. Cytotechnology 29 (3), 177. doi:10.1023/A:1008008021481.

Wechselberger, P., Sagmeister, P., Herwig, C., 2013. Model-based analysis on the extractability of information from data in dynamic fed-batch experiments. Biotechnol. Prog. 29 (1), 285-296. doi:10.1002/btpr.1649.

Werner, S., Kaiser, S.C., Kraume, M., Eibl, D., 2014. Computational fluid dynamics as a modern tool for engineering characterization of bioreactors. Pharm. Bioprocess. $2(1), 85-99$.

Wurm, F.M., 2004. Production of recombinant protein therapeutics in cultivated mammalian cells. Nat. Biotechnol. 22 (11), 1393.

Xing, Z., Bishop, N., Leister, K., Li, Z.J., 2010. Modeling kinetics of a large-scale fedbatch $\mathrm{CHO}$ cell culture by markov chain monte carlo method. Biotechnol. Prog. 26 (1), 208-219. doi:10.1002/btpr.284.

Xing, Z., Kenty, B.M., Li, Z.J., Lee, S.S., 2009. Scale-up analysis for a $\mathrm{CHO}$ cell culture process in large-scale bioreactors. Biotechnol. Bioeng. 103 (4), 733-746. doi:10. 1002 /bit.22287.

Zalai, D., Koczka, K., Parta, L, Wechselberger, P., Klein, T, Herwig, C, 2015. Combining mechanistic and data-driven approaches to gain process knowledge on the control of the metabolic shift to lactate uptake in a fed-batch $\mathrm{CHO}$ process. Biotechnol. Prog. 31 (6), 1657-1668. doi:10.1002/btpr.2179.

Zeng, A.-P., Deckwer, W.-D., Hu, W.-S., 1998. Determinants and rate laws of growth and death of hybridoma cells in continuous culture. Biotechnol. Bioeng. 57 (6), 642-654.

Zhou, M., Crawford, Y., Ng, D., Tung, J., Pynn, A.F., Meier, A., Yuk, I.H., Vijayasankaran, N., Leach, K., Joly, J., Snedecor, B., Shen, A., 2011. Decreasing lactate level and increasing antibody production in chinese hamster ovary cells (CHO) by reducing the expression of lactate dehydrogenase and pyruvate dehydrogenase kinases. J. Biotechnol. 153 (1), 27-34. doi:10.1016/j.jbiotec.2011.03.003. 